\title{
Pearls \& Oy-sters: A Novel Presentation of Ataxia With Vitamin E Deficiency Caused by TTPA Gene Mutation
}

Alonso Zea Vera, MD, Wei Liu, MD, Cameron Thomas, MD, MS, and Donald L. Gilbert, MD, MS

Neurology ${ }^{\circledR}$ 2021;96:e640-e642. doi:10.1212/WNL.0000000000010853

\section{Pearls}

- Ataxia with isolated vitamin E deficiency can present with a phenotype similar to a complex hereditary spastic paraplegia with dystonia and bradykinesia, but absent cerebellar ataxia or proprioceptive deficits.

- Despite being rare, prompt recognition of ataxia with vitamin E deficiency is critical as supplementation stops disease progression in most cases.

\section{Oy-sters}

- With increased availability of genetic testing, phenotypes of classic diseases are constantly expanding. It is important to be vigilant to atypical presentations.

- Nutritional vitamin E deficiency is extremely rare in the United States. If found, it should be thoroughly investigated.

\section{Case Report}

A 17-year-old boy with a medical history of asthma presented to the emergency department (ED) due to abnormal gait. His symptoms started 1 year before the presentation and had progressed slowly. He reported increased difficulty taking steps, which was more noticeable when running or with various athletics such as dribbling during soccer or running the bases in baseball. More recently, he started having problems going up and down stairs. His handwriting had also deteriorated and he described it as "more effortful." No weakness, sensory symptoms, or abnormal movements were reported. He had a nonsignificant surgical and birth history. He has a maternal uncle who developed an acute diplegia of unclear cause at age 16, necessitating wheelchair use since symptom onset.

The patient's examination showed spastic dysarthria and diffuse symmetric hyperreflexia with 3-4 beats of ankle clonus bilaterally. Eye movements, tone, and strength were normal. No dysmetria was noted. His gait was narrow-based with scissoring. Proprioception and all other sensory modalities were preserved. He had a negative Romberg. See the video for key findings in the physical examination. Initial laboratory studies including C-reactive protein, complete blood count, complete metabolic panel, thyroid-stimulating hormone/T4, vitamin $\mathrm{B}_{12}$, folic acid, and creatinine kinase were normal. After consultation with neurology, a brain and spinal MRI was obtained in the ED to rule out neoplasm. These results were normal and the patient was sent home with close outpatient follow-up.

The patient presented to the clinic 4 weeks later. In addition to previous findings, his examination showed bilateral slow finger and foot tapping. He also had dystonic movements including thumb adduction and, while running, overflow flexion of hips and left arm. He was started on a 4-week levodopa trial (maximum dose $8 \mathrm{mg} / \mathrm{kg} / \mathrm{d}$ ) without benefit. Baclofen
Correspondence

Dr. Zea Vera

Alonso.ZeaVera@cchmc.org

MORE ONLINE

- Video 
(maximum dose $30 \mathrm{mg}$ per day) and trihexyphenidyl (maximum dose $10 \mathrm{mg} / \mathrm{d}$ ) were tried for symptomatic relief. They were stopped due to side effects without any benefit. His symptoms remained stable over the next 9-12 months.

CSF neurotransmitters (8 months after discontinuation of levodopa), dystonia panel (300 genes), and mitochondrial DNA (sequence/del-dup) were negative. The patient had a normal nerve conduction study (NCS) and EMG. Additional laboratory evaluation revealed normal lipid panel, vitamin A, vitamin $\mathrm{D}$, and coenzyme Q10 levels. However, serum vitamin $\mathrm{E}$ level was undetectable. An evaluation by gastroenterology showed no signs of generalized malabsorption. He had a normal ophthalmologic and cardiac evaluation.

Whole-exome sequencing showed 2 pathogenic mutations in the TTPA gene (c.400C > T; c.513_514insTT), confirming the diagnosis of ataxia with isolated vitamin $\mathrm{E}$ deficiency (AVED). Both of these mutations have been reported before in patients with the classic presentation of AVED. Treatment was initiated with vitamin E supplementation, currently 2,000 units per day. Serum vitamin E levels have normalized (last level $5.3 \mu \mathrm{g} / \mathrm{mL}$ ). The patient's examination has remained stable except for a new mild proprioceptive deficit in the lower extremities, which was noted after a brief interruption of vitamin E. At the most recent follow-up, almost 2 years after the initial presentation, the patient showed no signs of cerebellar ataxia.

\section{Discussion}

We report a patient with a novel phenotype of AVED. Recognition of this disease is critical as prompt treatment with vitamin $\mathrm{E}$ can halt disease progression and limit disability. AVED is an autosomal recessive ataxia caused by a mutation in the TTPA gene. ${ }^{1,2}$ The global prevalence is unknown but appears to be more frequent in the North Africa and the Mediterranean region. A recent Algerian study found that it was the most common autosomal recessive ataxia after Friedreich ataxia, although cases of ataxia-telangiectasia may have been underrepresented. ${ }^{3}$ AVED generally presents in late childhood or the early teen years. Traditionally, the cardinal symptoms of AVED have been described as cerebellar ataxia, proprioceptive deficits, and absent or decreased deep tendon reflexes. ${ }^{1,2}$ Dystonia, myoclonus, retinitis pigmentosa, bladder disturbances, and cardiomyopathy can also occur. ${ }^{1}$ The most common initial symptoms are ataxia, head titubation, and dysarthria. ${ }^{1}$ Rarely, dystonia has been described as the initial symptom. ${ }^{4}$

Our patient presented with a year of progressive worsening gait due to spasticity of the lower extremities. He also showed dystonia and slowed alternating movements. Interestingly, he showed no signs of cerebellar ataxia or peripheral neuropathy and his reflexes were increased. Although brisk reflexes have been reported in AVED, this is extremely rare. ${ }^{1}$ NCS/EMG did not show signs of neuropathy; however, it has been reported that $53 \%$ of patients with AVED have normal or mild results in NCS/EMG. ${ }^{1}$ Given these initial symptoms, the diagnostic approach was originally focused on genetic dystonias and complex spastic paraplegia syndromes associated with bradykinesia that could present in the teen years.

Dystonia syndromes in the differential diagnosis should include DYT5a, DYT12, and DYT16. DYT5a is the classic form of dopa-responsive dystonia. Although it generally presents during childhood, later onset has also been described. It can be associated with parkinsonism, especially when the onset is after 15 years. Spasticity is uncommon and $56 \%-80 \%$ of patients present a diurnal fluctuation of symptoms. ${ }^{5}$ DYT 12 is characterized by an abrupt onset over hours to weeks of dystonia with or without parkinsonism. Most of the time, symptoms do not respond to levodopa and spasticity is rare. ${ }^{6}$ DYT16 can present as pure dystonia or dystoniaparkinsonism. It does not respond to levodopa. Brisk reflexes and spasticity have been reported. ${ }^{7}$

Complex hereditary spastic paraplegias and related disorders should also be considered. SPG11 and SPG15 have been associated with dystonia and parkinsonism, which can be levodopa-responsive. They are associated with characteristic MRI findings including a thin corpus callosum and the ears of the lynx sign. ${ }^{8}$ SPG7 can also present with spasticity and dystonia; however, the lack of cerebellar ataxia would be rare. ${ }^{8}$ Spinocerebellar ataxia 3, or Machado-Joseph disease, can present with a progressive pyramidal syndrome associated with a variable degree of a dystonic-rigid syndrome. It would be unusual to have no cerebellar ataxia or oculomotor abnormalities. ${ }^{9}$ Autosomal recessive ataxia of CharlevoixSaguenay is also associated with spasticity and, rarely, dystonia. It would be uncommon to present without cerebellar ataxia. ${ }^{10}$

The finding of low vitamin $\mathrm{E}$ was unexpected in our patient. Dietary vitamin E deficiency is extremely rare in the United States. Conditions that cause fat malabsorption can result in vitamin $\mathrm{E}$ deficiency; however, this was ruled out by normal levels of other fat-soluble vitamins. Abetalipoproteinemia is another cause of vitamin E deficiency but would be expected to cause low levels of low-density lipoprotein and other fatsoluble vitamins. The only condition causing isolated vitamin $\mathrm{E}$ deficiency is AVED. In AVED, intestinal vitamin $\mathrm{E}$ absorption is normal, but mutations of TTPA impair the hepatic incorporation of $\alpha$-tocopherol in very-low-density lipoprotein, resulting in low levels of plasma vitamin E. ${ }^{1}$

The treatment of AVED is high-dose vitamin E supplementation to normalize blood levels. Prompt treatment is critical as it stops disease progression in most cases. ${ }^{1}$ Improvement of symptoms has been reported, especially if they have not been present for a long time, but this is rare and should not be the goal of therapy. ${ }^{1,2}$ In the largest cohort of patients published, all patients treated before the bedridden stage continued to walk independently, and one patient regained ambulation. ${ }^{1}$ 
Treatment of asymptomatic patients can prevent symptoms from developing. ${ }^{1}$ Rarely, the disease can progress despite vitamin E supplementation. ${ }^{2}$

This case underscores the importance of critically appraising very abnormal laboratory results, even when the clinical findings appear not to fit the known phenotype, and broadens the phenotypic variability of AVED. With the increased availability of genetic testing, new phenotypes of known genes are being described. As neurologists, we have an organized and methodical approach to patients based on their clinical characteristics and previously reported cases. However, we should be ready to think outside the box when a patient does not seem to accommodate these rules, as there is still substantial uncertainty in our field.

\section{Study Funding}

No targeted funding.

\section{Disclosure}

A. Zea Vera, W. Liu, and C. Thomas report no financial disclosures. D.L. Gilbert has received honoraria and/or travel support from the Tourette Association of America/Centers for Disease Control and Prevention, the Child Neurology Society, and the American Academy of Neurology; compensation for expert testimony for the US National Vaccine Injury Compensation Program through the Department of Health and Human Services; and payment for medical expert opinions through Advanced Medical/Teladoc. D.L. Gilbert has received research support from the NIH (NIMH, NINDS); salary compensation through Cincinnati Children's for work as a clinical trial site investigator from Emalex (clinical trial, Tourette syndrome) and EryDel (clinical trial, Ataxia Telangiectasia); and book royalties from Elsevier and Wolters Kluwer. Go to Neurology.org/N for full disclosures.
Appendix Authors

\begin{tabular}{lll}
\hline Name & Location & Contribution \\
\hline $\begin{array}{l}\text { Alonso Zea } \\
\text { Vera, MD }\end{array}$ & $\begin{array}{l}\text { Cincinnati Children's } \\
\text { Hospital Medical } \\
\text { Center, OH }\end{array}$ & $\begin{array}{l}\text { Design and conceptualization of } \\
\text { the study, drafting of initial } \\
\text { manuscript, review and approval } \\
\text { of finalized manuscript }\end{array}$ \\
\hline Wei Liu, MD & $\begin{array}{l}\text { Cincinnati Children's } \\
\text { Hospital Medical }\end{array}$ & $\begin{array}{l}\text { Design and conceptualization of } \\
\text { the study, review and approval of } \\
\text { finalized manuscript }\end{array}$ \\
\hline $\begin{array}{l}\text { Cameron } \\
\text { Thomas, } \\
\text { MD, MS }\end{array}$ & $\begin{array}{l}\text { Cincinnati Children's } \\
\text { Cospital Medical }\end{array}$ & $\begin{array}{l}\text { Design and conceptualization of } \\
\text { the study, review and approval of } \\
\text { finalized manuscript }\end{array}$ \\
$\begin{array}{l}\text { Center, OH } \\
\text { Dilbert, } \\
\text { MD, MS }\end{array}$ & $\begin{array}{l}\text { Cincinnati Children's } \\
\text { Cospital Medical }\end{array}$ & $\begin{array}{l}\text { Design and conceptualization of } \\
\text { the study, review and approval of } \\
\text { finalized manuscript }\end{array}$ \\
\hline
\end{tabular}

\section{References}

1. El Euch-Fayache G, Bouhlal Y, Amouri R, Feki M, Hentati F. Molecular, clinical and peripheral neuropathy study of Tunisian patients with ataxia with vitamin $\mathrm{E}$ deficiency. Brain 2014;137:402-410.

2. Mariotti C, Gellera C, Rimoldi M, et al. Ataxia with isolated vitamin E deficiency: neurological phenotype, clinical follow-up and novel mutations in TTPA gene in Italian families. Neurol Sci 2004;25:130-137.

3. Hamza W, Ali Pacha L, Hamadouche T, et al. Molecular and clinical study of a cohort of 110 Algerian patients with autosomal recessive ataxia. BMC Med Genet 2015;16: 36.

4. Pradeep S, Ali T, Guduru Z. Ataxia with vitamin E deficiency with predominant cervical dystonia. Mov Disord Clin Pract 2020;7:100-103.

5. Wijemanne S, Jankovic J. Dopa-responsive dystonia-clinical and genetic heterogeneity. Nat Rev Neurol 2015;11:414-424.

6. Rosewich H, Sweney MT, DeBrosse S, et al. Research conference summary from the 2014 international task force on ATP1A3-related disorders. Neurol Genet 2017;3: e139.

7. Camargos S, Scholz S, Simon-Sanchez J, et al. DYT16, a novel young-onset dystoniaparkinsonism disorder: identification of a segregating mutation in the stress-response protein PRKRA. Lancet Neurol 2008;7:207-215.

8. Shribman S, Reid E, Crosby AH, Houlden H, Warner TT. Hereditary spastic paraplegia: from diagnosis to emerging therapeutic approaches. Lancet Neurol 2019;18: $1136-1146$.

9. D’Abreu A, Franca MC Jr, Paulson HL, Lopes-Cendes I. Caring for Machado-Joseph disease: current understanding and how to help patients. Parkinsonism Relat Disord 2010;16:2-7.

10. Pilliod J, Moutton S, Lavie J, et al. New practical definitions for the diagnosis of autosomal recessive spastic ataxia of Charlevoix-Saguenay. Ann Neurol 2015;78: $871-886$. 


\section{Neurology}

\section{Pearls \& Oy-sters: A Novel Presentation of Ataxia With Vitamin E Deficiency Caused by TTPA Gene Mutation}

Alonso Zea Vera, Wei Liu, Cameron Thomas, et al.

Neurology 2021;96;e640-e642 Published Online before print September 14, 2020

DOI 10.1212/WNL.0000000000010853

This information is current as of September 14, 2020

Updated Information \&

Services

References

Subspecialty Collections

Permissions \& Licensing

Reprints including high resolution figures, can be found at:

http://n.neurology.org/content/96/4/e640.full

This article cites 10 articles, 1 of which you can access for free at: http://n.neurology.org/content/96/4/e640.full\#ref-list-1

This article, along with others on similar topics, appears in the following collection(s):

All Movement Disorders

http://n.neurology.org/cgi/collection/all_movement_disorders Dystonia

http://n.neurology.org/cgi/collection/dystonia

Spastic paraplegia

http://n.neurology.org/cgi/collection/spastic_paraplegia

Information about reproducing this article in parts (figures,tables) or in its entirety can be found online at:

http://www.neurology.org/about/about_the_journal\#permissions

Information about ordering reprints can be found online:

http://n.neurology.org/subscribers/advertise

Neurology ${ }^{\circledR}$ is the official journal of the American Academy of Neurology. Published continuously since 1951, it is now a weekly with 48 issues per year. Copyright (O) 2020 American Academy of Neurology. All rights reserved. Print ISSN: 0028-3878. Online ISSN: 1526-632X.

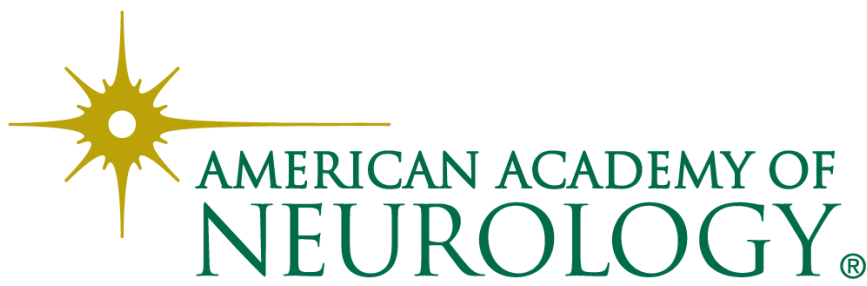

